\title{
UM BREVE HISTÓRICO DA EDUCAÇÃO INCLUSIVA: CARACTERÍSTICAS DO ATENDIMENTO EDUCACIONAL ESPECIALIZADO
}

\section{ARTIGO ORIGINAL}

RODRIGUES, Murilo Raposo ${ }^{1}$

RODRIGUES, Murilo Raposo. Um breve histórico da Educação Inclusiva: Características do atendimento educacional especializado. Revista Científica Multidisciplinar Núcleo do Conhecimento. Ano 05, Ed. 10, Vol. 13, pp. 164-174. Outubro de 2020. ISSN: 2448-0959, Link de acesso: https://www.nucleodoconhecimento.com.br/educacao/caracteristicas-do-atendimento

\section{RESUMO}

Trata-se de uma análise sobre a trajetória da educação especial no Brasil, percorrendo um caminho de 26 anos desde a Declaração de Salamanca, onde foi determinado que toda criança deve ter o direito à educação preservado, até os dias atuais. Como base para estudos, examinamos: alguns livros e artigos científicos de determinados autores dessa área, a Lei de Diretrizes e Bases da Educação Nacional, a Constituição Federal de 1988 e o documento elaborado na Conferência Mundial sobre Educação Especial no encontro promovido pelas Nações Unidas em Salamanca, na Espanha, no ano de 1994. Através deste estudo, evidenciamos que, apesar de termos avançado bastante com o debate sobre esta temática entre os profissionais da educação, ainda se faz necessário nos aprofundarmos nas reflexões sobre como implantar uma escola que realmente proporcione acessibilidade às crianças portadoras de necessidades especiais e, outro aspecto também muito

\footnotetext{
${ }^{1}$ Pós-Graduação em Libras e Educação Inclusiva da Pessoa Surda (Faculdade Santa Emília); Licenciatura em Educação Artística - Habilitação em Artes Cênicas (Universidade Federal de Pernambuco).
} 
importante, criar um ambiente de acolhimento para esses alunos, envolvendo toda a comunidade escolar neste projeto de inclusão e formação da cidadania.

Palavras-chave: Educação Especial, acessibilidade, Comunidade Escolar, inclusão.

\section{INTRODUÇÃO}

$\mathrm{Na}$ história da educação de crianças portadoras de algum tipo de necessidade especial, podemos observar que, até alguns anos atrás, constatávamos diversos paradigmas de natureza excludente em relação ao processo de ensino-aprendizagem desses alunos. Na trajetória da Educação Especial, era notável a exclusão dessas pessoas como cidadãos plenos, observando-se desde o impedimento do seu convívio em sociedade, sem poderem usufruir de espaços comuns de convivência social, a ações que segregavam esses indivíduos às salas de aulas da Educação Especial para estimular suas capacidades, com um olhar parcial mais voltado para a "doença" e para as limitações, do que propriamente para as suas potencialidades.

Apesar do conceito de inclusão estar sendo sempre discutido amplamente por estudiosos da Educação, infelizmente este tema ainda pode ser mal compreendido por algumas pessoas, pois frequentemente presenciamos expressões como "sala de inclusão" até mesmo dentro da própria comunidade escolar.

Desta forma, vale destacar que a inclusão deve ser um exemplo que precisamos difundir e aplicar nos mais variados espaços, sejam eles de âmbito educacional, simbólico, cultural, físico e social, pois a partir da inclusão podemos reconhecer cada indivíduo na diversidade de suas especificidades, suas identidades, seus gêneros, suas características, suas heranças culturais, suas descendências, etc.

Como afirma Camargo (2017, p. 1), "inclusão, portanto, é uma prática social que se aplica no trabalho, na arquitetura, no lazer, na educação, na cultura, mas, principalmente, na atitude e no perceber das coisas, de si e do outrem". 
A partir deste contexto, devemos exercitar esse olhar para cada indivíduo, pois, de acordo com Mantoan (2006, p. 7-8), "[...] há diferenças e há igualdades, e nem tudo deve ser igual nem tudo deve ser diferente, [...] é preciso que tenhamos o direito de ser diferente quando a igualdade nos descaracteriza e o direito de ser iguais quando a diferença nos inferioriza".

De grande importância para o processo de inclusão dentro dos ambientes da escola, a implantação das salas de Atendimento Educacional Especializado (AEE) a partir dos anos 2000, favoreceu debates nos mais variados espaços como cursos de Formação Continuada, Projetos Político Pedagógicos, reuniões com a comunidade escolar, entre outros. E ainda existem muitos aspectos na sua implementação que devem ser discutidos, avaliados e esclarecidos junto aos profissionais da Educação para que os objetivos sejam realmente alcançados, como o desenvolvimento social e cognitivo dos alunos especiais, como também, e não menos importante, a sua interação com os outros alunos.

\section{HISTORICIDADE}

Partindo do pressuposto de que estudar a nossa história é imprescindível para compreendermos a nossa realidade na Educação, neste aspecto, Saviani (1990) observa que as mudanças históricas que ocorrem em nossa sociedade, de certa forma, influenciam a educação, e esta, por sua vez, contribui para essas transformações. Assim, devemos analisar os marcos políticos da Educação Especial no contexto referente ao Atendimento Educacional Especializado e às Salas de Recursos Multifuncionais (SRM's) implementadas em muitas escolas brasileiras.

O Inciso III, do artigo 208, da nossa Constituição Federal de 1988, garante que "[...] o dever do Estado com a educação será efetivado mediante a garantia de atendimento educacional especializado aos portadores de deficiência, preferencialmente na rede regular de ensino" (BRASIL, 2020, n. p.). Nesta época, não havia um precedente legal, nem estudos teóricos aprofundados para a implementação imediata do Atendimento Educacional Especializado nas redes regulares de ensino. 
Em 2007, um grupo de colaboradores, incluindo profissionais e pesquisadores da área da Educação, juntamente com membros da Secretaria de Educação Especial do MEC (Ministério da Educação e Cultura), começou a elaborar um documento que foi entregue ao então Ministro da Educação Fernando Haddad, em 07 de janeiro de 2008, intitulado Política Nacional de Educação Especial na Perspectiva da Educação Inclusiva, onde apresenta, no item IV, o objetivo da Educação Especial nas redes de ensino:

[...] tem como objetivo assegurar a inclusão escolar de alunos com deficiência, transtornos globais do desenvolvimento e altas habilidades/superdotação, orientando os sistemas de ensino para garantir: acesso ao ensino regular, com participação, aprendizagem e continuidade nos níveis mais elevados do ensino; transversalidade da modalidade de educação especial desde a educação infantil até a educação superior; oferta do atendimento educacional especializado; formação de professores para o atendimento educacional especializado e demais profissionais da educação para a inclusão; participação da família e da comunidade; acessibilidade arquitetônica, nos transportes, nos mobiliários, nas comunicações e informação; e articulação intersetorial na implementação das políticas públicas. (BRASIL, 2008, p. 14)

Desta forma, podemos aferir que sob a perspectiva da Educação Inclusiva, a Política Nacional de Educação Especial tem como principal objetivo, assegurar a inclusão escolar de todos os alunos com deficiência, transtornos globais do desenvolvimento e altas habilidades/superdotação, orientando que os sistemas de ensino garantam a esses alunos o acesso ao ensino regular, com participação e envolvimento de todos os profissionais da escola.

O Atendimento Educacional Especializado, nos termos do documento já antes citado - Política Nacional de Educação Especial na Perspectiva da Educação Inclusiva - é um importante instrumento para se alcançar os objetivos imediatamente acima elencados, pois é por meio dele que se:

[...] identifica, elabora e organiza recursos pedagógicos e de acessibilidade que eliminem as barreiras para a plena participação dos alunos, considerando as suas necessidades específicas. As atividades desenvolvidas no atendimento educacional especializado diferenciam-

Disponível em: https://www.nucleodoconhecimento.com.br/educacao/caracteristicas-do- 
se daquelas realizadas na sala de aula comum, não sendo substitutivas à escolarização. Esse atendimento complementa e/ou suplementa a formação dos alunos com vistas à autonomia e independência na escola e fora dela. (BRASIL, 2008, p. 16)

Sendo assim, o AEE e as SRM's têm um importante papel como facilitadores na elaboração de atividades e na providência de materiais pedagógicos que estimulem o aprendizado dos alunos com necessidades especiais, além da orientação das professoras e famílias.

Em relação às atividades a serem desenvolvidas pelo $A E E$, o documento elaborado em 2007 e entregue ao ministro da educação em 2008 esclarece que:

O atendimento educacional especializado disponibiliza programas de enriquecimento curricular, o ensino de linguagens e códigos específicos de comunicação e sinalização, ajudas técnicas e tecnologia assistiva, dentre outros. Ao longo de todo processo de escolarização, esse atendimento deve estar articulado com a proposta pedagógica do ensino comum. (BRASIL, 2008, p. 16)

\section{FORMAÇÃO}

A partir dessas colocações, procuramos refletir sobre como seria a relação do Atendimento Educacional Especializado com os Projetos Políticos Pedagógicos (PPP) nas escolas. Este, por sua vez, ao ser elaborado com a ajuda de toda a comunidade escolar, indica uma direção a ser seguida por gestores, professores, funcionários, alunos e pais para alcançar objetivos que estão propostos no PPP.

Outro ponto importante a se considerar é sobre as possibilidades que o trabalho que é desenvolvido pelo AEE nas necessidades específicas de cada aluno:

O atendimento educacional especializado é realizado mediante a atuação de profissionais com conhecimentos específicos no ensino da Língua Brasileira de Sinais, da Língua Portuguesa na modalidade escrita como segunda língua, do sistema Braille, do Soroban, da orientação e mobilidade, das atividades de vida autônoma, da comunicação alternativa, do desenvolvimento dos processos mentais superiores, dos programas de enriquecimento curricular, da adequação e produção de 
materiais didáticos e pedagógicos, da utilização de recursos ópticos e não ópticos, da tecnologia assistiva e outros. (BRASIL, 2008, p. 17)

Neste sentido, impõe-se a reflexão acerca da necessidade da formação de todo o corpo docente de uma escola e, principalmente, da formação dos professores que atuam no Atendimento Educacional Especializado e nas Salas de Recursos Multifuncionais.

O artigo 87 das Disposições Transitórias da Lei de Diretrizes e Bases (LDB) designou como a "Década da Educação" o decênio seguinte à sua publicação, ampliando este debate sobretudo a partir do final de 1997 , instituindo, ainda, em seu $\S^{\circ}{ }^{\circ}$, que todos os professores da Educação Básica necessitariam ser habilitados em nível superior ou deveriam ser formados por treinamento em serviço.

Devemos ressaltar, contudo, que o suso citado dispositivo da LDB restou tacitamente revogado pelo artigo 62 do mesmo diploma legal, com a redação que lhe foi dada pela Lei ํo 13.415/2017. Desta forma, os professores com formação em cursos de nível médio, na modalidade normal, encontram-se habilitados a exercer a docência na Educação Infantil e no Fundamental I:

Art. 62. A formação de docentes para atuar na educação básica far-se-á em nível superior, em curso de licenciatura plena, admitida, como formação mínima para o exercício do magistério na educação infantil e nos cinco primeiros anos do ensino fundamental, a oferecida em nível médio, na modalidade normal. (BRASIL, 2017, n. p.)

É imprescindível ressaltarmos que a graduação e a Formação Continuada devem fazer parte de um programa educacional onde os professores recebam a oportunidade de renovar seus conhecimentos e que este seja um aspecto a ser valorizado pelas Secretarias de Educação de cada estado e município, como também observar as condições de trabalho em cada escola e os recursos destinados especificamente à Educação Especial (GATTI, 1998).

Deste modo, nos termos da Lei o 9.394, de 20 de dezembro de 1996, determina:

Art. 63. Os institutos superiores de educação manterão: 
I - cursos formadores de profissionais para a educação básica, inclusive o curso normal superior, destinado à formação de docentes para a educação infantil e para as primeiras séries do ensino fundamental [...]. (BRASIL, 1996, n. p.)

Destacamos também que todo o trabalho pedagógico, com recursos e propostas pedagógicas específicas, deve estar sempre em constante debate e requer investimento, preparação, estudo, suporte, vivência e análise, além da troca de informações com profissionais de outras áreas do conhecimento.

O Decreto № 6.571 , de 17 de dezembro de 2008, já revogado pelo Decreto № 7.611 de 2011, determinava que o Atendimento Educacional Especializado seria financiado por meio do Fundo de Manutenção e Desenvolvimento da Educação Básica e da Valorização dos Profissionais da Educação (Fundeb). Neste Decreto, o Governo Federal se comprometia a prestar apoio financeiro e técnico aos sistemas públicos de ensino dos Estados, do Distrito Federal e dos Municípios, e apresentava, outrossim, como prioridade, o aumento da oferta do AEE aos alunos com deficiência, transtornos globais do desenvolvimento e altas habilidades ou superdotação matriculados na rede pública de ensino regular.

Todavia, conforme já antecipava acima, o Decreto ํㅜ 7.611 de 17 de novembro de 2011 revogou as disposições anteriores acerca do Atendimento Educacional Especializado, estabelecendo novas e diversas providências sobre a Educação Especial. Com efeito, o artigo $1^{\circ}$ do novel diploma legal, estabelece que:

Art. 1ํ $\mathrm{O}$ dever do Estado com a educação das pessoas público-alvo da educação especial será efetivado de acordo com as seguintes diretrizes:

I - garantia de um sistema educacional inclusivo em todos os níveis, sem discriminação e com base na igualdade de oportunidades;

II - aprendizado ao longo de toda a vida;

III - não exclusão do sistema educacional geral sob alegação de deficiência;

IV - garantia de ensino fundamental gratuito e compulsório, asseguradas adaptações razoáveis de acordo com as necessidades individuais; 
V - oferta de apoio necessário, no âmbito do sistema educacional geral, com vistas a facilitar sua efetiva educação;

VI - adoção de medidas de apoio individualizadas e efetivas, em ambientes que maximizem o desenvolvimento acadêmico e social, de acordo com a meta de inclusão plena;

VII - oferta de educação especial preferencialmente na rede regular de ensino; e

VIII - apoio técnico e financeiro pelo Poder Público às instituições privadas sem fins lucrativos, especializadas e com atuação exclusiva em educação especial. (BRASIL, 2011, n. p.)

O artigo $2^{\circ}$ do mesmo édito legislativo ressalta que a Educação Especial precisa garantir um serviço especializado de apoio, sendo estes serviços considerados como o AEE, deliberando da seguinte da seguinte forma:

Art. 2o A educação especial deve garantir os serviços de apoio especializado voltado a eliminar as barreiras que possam obstruir o processo de escolarização de estudantes com deficiência, transtornos globais do desenvolvimento e altas habilidades ou superdotação.

§ 1ํ Para fins deste Decreto, os serviços de que trata o caput serão denominados atendimento educacional especializado, compreendido como o conjunto de atividades, recursos de acessibilidade $\mathrm{e}$ pedagógicos organizados institucional e continuamente, prestado das seguintes formas:

I - complementar à formação dos estudantes com deficiência, transtornos globais do desenvolvimento, como apoio permanente e limitado no tempo e na frequência dos estudantes às salas de recursos multifuncionais; ou

II - suplementar à formação de estudantes com altas habilidades ou superdotação.

$\S 2^{\circ} \mathrm{O}$ atendimento educacional especializado deve integrar a proposta pedagógica da escola, envolver a participação da família para garantir pleno acesso e participação dos estudantes, atender às necessidades específicas das pessoas público-alvo da educação especial, e ser realizado em articulação com as demais políticas públicas. (BRASIL, 2011, n. p.) 
Desta forma, o Governo Federal, através da elaboração deste documento, aponta o conjunto de ações a serem implementadas nas SRM's, sem direcionar especificamente como essas atividades devem ser desenvolvidas pelos professores especializados. Na realidade, a prática do professor, a sua vivência com cada aluno é que vai direcionar seu planejamento de trabalho.

Portanto, ainda no Decreto no 7.611, o Governo Federal valida o direito ao conhecimento e desenvolvimento pedagógico dos alunos com necessidades educativas especiais, ressaltando em seu artigo $3^{\circ}$ os objetivos que devem ser compreendidos no AEE:

I - prover condições de acesso, participação e aprendizagem no ensino regular e garantir serviços de apoio especializados de acordo com as necessidades individuais dos estudantes;

II - garantir a transversalidade das ações da educação especial no ensino regular;

III - fomentar o desenvolvimento de recursos didáticos e pedagógicos que eliminem as barreiras no processo de ensino e aprendizagem; e

IV - assegurar condições para a continuidade de estudos nos demais níveis, etapas e modalidades de ensino. (BRASIL, 2011, n. p.)

Sobre a metodologia que devemos elaborar para estimular o conhecimento do alunado, Camargo (2017, p. 3-4) propõe:

A estrutura proposta pelo desenho universal pressupõe a diversidade e o trabalho com identidade e diferença em sua constituição. Metodologia, processo de comunicação e material instrucional pensado sobre a estrutura referida precisam ser aplicados para toda a sala de aula, devendo ser contemplado na metodologia, processo de comunicação e material instrucional, elementos próprios dos princípios da diversidade, identidade e diferença, e não da homogeneidade e dos espaços homogeneizantes, esses últimos produtos de construção social. 


\section{AFETIVIDADE}

Enquanto que a escola tem um papel fundamental na propagação do conhecimento, algumas vezes percebemos que ainda é concebido uma forma de ensino que prioriza o intelecto e desaprecia o lado afetivo e emocional, não dando a devida importância de que o ser humano é um indivíduo cuja intelectualidade e emoção unem-se e, desta forma, influencia no desenvolvimento cognitivo e que pode deixar lacunas na formação integral dos educandos. Em relação à Educação Especial, se não exercitarmos a inclusão reproduzimos os moldes de nossa sociedade, na qual ainda há exclusão social, pois segue uma mesma linha de estrutura da educação tradicional (COELHO; SCHMIDT, 2018).

$\mathrm{Na}$ função do professor que atua nas SRM's, ressaltamos que existe a importante necessidade de aprender com o aluno que busca o atendimento, entender seu mundo interno, estabelecendo com ele um vínculo afetivo para que esse aluno possa se sentir confiante e motivado para participar e colaborar com as atividades que the são propostas, além de precisarmos ter sensibilidade para perceber como podemos trabalhar os conteúdos com estes alunos.

Nesta modalidade de atendimento pedagógico, há que se ressaltar o respeito às peculiaridades de cada aluno, seus processos individuais onde o professor vai conhecendo sua sociabilidade, seus limites, sua cognição, seu modo de ser e estar no mundo (PIAGET, 1975).

Se torna de suma importância estimular nos alunos o ingresso ao simbolismo da cultura que foi assimilada e ampliada pelo ser humano ao longo de sua história. Segundo Vygotsky, Luria e Leontiev (2010), a aprendizagem tem uma característica autônoma, não é apenas um caminho para desenvolver as capacidades mentais, mas, por si só, propicia transformação.

Ao ingressar na escola, o aluno precisa se sentir acolhido e aceito, necessita ser percebido como um ser em construção. Neste sentido, devemos considerar a sua 
história particular de vida que antecede à sua convivência escolar, o que certamente será essencial neste processo ensino-aprendizagem.

Segundo Alves (2002, p. 6):

Toda experiência de aprendizagem se inicia com uma experiência afetiva. É a fome que põe em funcionamento o aparelho pensador. Fome é afeto. O pensamento nasce do afeto, nasce da fome. Não confundir afeto com beijinhos e carinhos. Afeto, do latim "afettare", quer dizer "ir atrás". É o movimento da alma na busca do objeto de sua fome. É o Eros platônico, a fome que faz a alma voar em busca do fruto sonhado".

Procurarmos o que tem significado para os alunos com necessidades especiais, dentro de temas contextualizados que sejam concretamente importantes para eles e que estejam relacionados às suas vivências, partindo do conhecimento prévio que eles já possuem para transformar conteúdos simples em conteúdos mais complexos, deve ser o objetivo dos professores das SRM's para poderem estimular o desenvolvimento social e cognitivo dessas crianças.

De acordo com Piaget (apud OLIVEIRA, 1992), o desenvolvimento intelectual está relacionado a dois importantes componentes: o afetivo e o cognitivo. Estes dois aspectos, na Educação, estão relacionados para estimular o processo de ensinoaprendizagem e alcançarmos os objetivos propostos nos planos pedagógicos. $\mathrm{Na}$ realidade, todas as crianças, com necessidades especiais ou não, têm potencialidades distintas, pois cada uma possui suas diferenças nos aspectos culturais, cognitivos, biológicos, físicos e psíquicos, quando são estimuladas e motivadas elas demonstram um maior interesse nos conteúdos e um melhor resultado no aprendizado.

Deste modo, quando se desenvolve uma relação de confiança e compromisso entre professores e alunos, esse envolvimento emocional e afetivo contribui para uma evolução no processo de aprendizagem, além de estabelecer uma melhora na relação social dos alunos com necessidades especiais com as demais crianças da escola (OLIVEIRA, 1992). 


\section{CONSIDERAÇÕES FINAIS}

Diante de todas as exposições e análises, de maneira a corroborar com o que defende Vygotsky (2005), podemos concluir que o aprendizado escolar exerce um papel fundamental e decisivo para que as crianças se conscientizem de seus processos cognitivos. Esses processos mentais que as crianças desenvolvem a partir da aprendizagem escolar, estimulam o pensamento crítico contribuindo, desta forma, na maneira de pensar e agir diante das situações cotidianas da vida. São processos em constante desenvolvimento e que não se estagnam. Estimular o aprendizado será sempre o ponto de partida para o desenvolvimento cognitivo de qualquer criança.

É necessário que o professor da Educação Especial compreenda que o aluno com necessidades especiais é um indivíduo complexo, contextualizado e pensante, reflexivo, e o seu desenvolvimento na aprendizagem tem uma correlação com os aspectos afetivos e cognitivos. Por isso, precisamos compreender que o entendimento dessas crianças acerca dos conteúdos trabalhados em sala de aula, enquanto sujeitos no processo ensino-aprendizagem, possui um nível cognitivo específico e singular que será desenvolvido a partir da relação afetiva entre o professor e o aluno. Além disso, é importante percebermos que cada aluno, nas suas especificidades, possui uma história proveniente das relações que foram estabelecidas previamente dentro do seu ambiente familiar, psicológico, cultural e social que antecedem o seu relacionamento com a escola (FERNANDEZ, 2001).

Salientamos ser imprescindível que a escola, enquanto ambiente de trabalho, de conhecimento, de criatividade, de estímulos e de reflexão, pondere sobre uma educação humanizada e afetiva para desenvolver em toda a comunidade escolar um ambiente de socialização entre os agentes envolvidos, como também um espaço de inclusão e, principalmente, de acolhimento dos seus alunos e um lugar que procura desenvolver as suas potencialidades individuais e coletivas, exercitando diariamente a construção da cidadania e o senso crítico em cada uma dessas crianças. 


\section{REFERÊNCIAS}

ALVES, Rubem. A arte de produzir fome. Folha de São Paulo, São Paulo, ano 82, n. 26872, 29 out. 2002. Sinapse, p. 6.

BRASIL. [Constituição (1988)]. Constituição da República Federativa do Brasil de 1988. Brasília, DF: Presidência da República, [2020]. Disponível em: http://www.planalto.gov.br/ccivil_03/constituicao/constituicao.htm. Acesso em: 01/04/2020.

BRASIL. Decreto № 7.611, de 17 de novembro de 2011. Dispõe sobre a educação especial, o atendimento educacional especializado e dá outras providências. Brasília, DF: Presidência da República, 2011. Disponível em: http://www.planalto.gov.br/ccivil_03/_ato2011-2014/2011/decreto/d7611.htm. Acesso em: 01/04/2020.

BRASIL. Lei nำ 13.415, de 16 de fevereiro de 2017. Altera as Leis $\mathrm{n} \cong 9.394$, de 20 de dezembro de 1996, [...] e 11.494, de 20 de junho 2007 [...]; revoga a Lei $n^{0} 11.161$, de 5 de agosto de 2005; e institui a Política de Fomento à Implementação de Escolas de Ensino Médio em Tempo Integral. Brasília, DF: Presidência da República, 2017. Disponível em: http://www.planalto.gov.br/ccivil_03/_ato20152018/2017/lei/l13415.htm. Acesso em: 01/04/2020.

BRASIL. Lei nํ 9.394, de 20 de dezembro de 1996. Estabelece as diretrizes e bases da Educação Nacional. Brasília, DF: Presidência da República, 1996. Disponível em: http://www.planalto.gov.br/ccivil_03/leis/19394.htm. Acesso em: 01/04/2020.

BRASIL. Ministério da Educação. Política Nacional de Educação Especial na Perspectiva da Educação Inclusiva. Brasília, DF: Ministério da Educação, 2008. Disponível em: http://portal.mec.gov.br/arquivos/pdf/politicaeducespecial.pdf. Acesso em: 01/04/2020. 
CAMARGO, Eder Pires de. Inclusão social, educação inclusiva e educação especial: enlaces e desenlaces. Ciência \& Educação, Bauru, v. 23, n. 1, p. 1-6, 2017.

COELHO, Rejane Texeira; SCHMIDT, Taciana Solange. Afetividade: por uma educação potencializadora e humanizadora na educação especial. In: PARANÁ. Secretaria de Estado da Educação. Superintendência de Educação. Os Desafios da Escola Pública Paranaense na Perspectiva do Professor. Curitiba: SEED/PR, 2018. v. 1. (Cadernos PDE). Disponível em: http://www.diaadiaeducacao.pr.gov.br/portals/cadernospde/pdebusca/ producoes _pde/2016/2016_artigo_edespecial_unioeste_tacianasolangeschmidt.pdf. Acesso em: 01/04/2020.

FERNANDEZ, Alícia. Os idiomas do aprendente: análise de modalidades ensinantes em famílias, escolas e meios de comunicação. Porto Alegre: Artmed, 2001.

GATTI, Bernadete Angelina. Curso de pedagogia em questão ou a questão da formação dos educadores. Nuances, São Paulo, v. 4, n. 4, p. 1-4, set. 1998.

MANTOAN, Maria Teresa Eglér. Inclusão escolar: O que é? Por quê? Como fazer? São Paulo: Moderna, 2006.

OLIVEIRA, Marta Kohl. O problema da afetividade em Vygotsky. In: LA TAILLE, Yves de; OLIVEIRA, Marta Kohl de; DANTAS, Heloysa (org.). Piaget, Vygotsky e Wallon: teorias psicogenéticas em discussão. São Paulo: Summus, 1992. p. 75-77.

PIAGET, Jean. A psicologia do desenvolvimento. São Paulo: Pioneira, 1975.

SAVIANI, Dermeval. A Nova Lei de Diretrizes e Bases. Pro-Posições, Campinas, v.1, n. 1, p. 7-13, mar. 1990.

VYGOTSKY, Lev. Pensamento e linguagem. 3. ed. São Paulo: Editora Martins Fontes, 2005. 
VYGOTSKY, Lev; LURIA, Alexander Romanovich; LEONTIEV, Alex. Linguagem, desenvolvimento e aprendizagem. 11. ed. São Paulo: Ícone Editora, 2010.

Enviado: Junho, 2020.

Aprovado: Outubro, 2020. 